\title{
Complementary
}

Medicine Research

Complement Med Res, DOI: 10.1159/000521783

Received: November 11, 2021

Accepted: January 4, 2022

Published online: January 5, 2022

\section{Evaluating Comparing the Effects of Massage Therapy and Aromatherapy on Knee Pain, Morning Stiffness, Daily Life Function, and Quality of Life in Patients with Knee Osteoarthritis}

Li M, Liu Z, Huang Y

ISSN: 2504-2092 (Print), elSSN: 2504-2106 (Online)

https://www.karger.com/CMR

Complementary Medicine Research

Disclaimer:

Accepted, unedited article not yet assigned to an issue. The statements, opinions and data contained in this publication are solely those of the individual authors and contributors and not of the publisher and the editor(s). The publisher and the editor(s) disclaim responsibility for any injury to persons or property resulting from any ideas, methods, instructions or products referred to the content.

Copyright:

(C) S. Karger AG, Basel 
Letter

Evaluating Comparing the Effects of Massage Therapy and Aromatherapy on Knee Pain, Morning Stiffness, Daily Life Function, and Quality of Life in Patients with Knee Osteoarthritis

Menghua Li ${ }^{a}$, Zhaoxi Liu ${ }^{b}$, Yunxuan Huang ${ }^{c}$

a Student Office, Guangzhou Xinhua University, Guangzhou, China

${ }^{b}$ Rehabilitation Center, Guangzhou Harmony Hospital, Guangzhou, China

${ }^{\mathrm{c}}$ Rehabilitation Nursing Center, the First Affiliated Hospital of Guangzhou University of Chinese Medicine, Guangzhou, China

Key words : Aromatherapy · Massage · Osteoarthritis · Quality of life · Pain

Short Title: letter to editor

Corresponding Author

Yunxuan Huang

Rehabilitation Nursing Center

the First Affiliated Hospital of Guangzhou University of Chinese Medicine

12 Airport Road, Baiyun District

Guangzhou, China

E-mail: 598990333@qq.com

\section{Dear Editor,}

We are very happy to read this article named "Comparing the Effects of Massage Therapy and Aromatherapy on Knee Pain, Morning Stiffness, Daily Life Function, and Quality of Life in Patients with Knee Osteoarthritis" [1]. The study confirmed that massage can effectively improve the quality of life of patients with knee osteoarthritis. This provides clinicians with good health advice. We greatly appreciate the author's research.

If the research design can be improved, then the research power will be stronger. The authors used simple randomization for patient assignments. Although simple randomization is inexpensive and easy to implement, it is easy to trigger imbalances in terms of important baseline differences [2]. Furthermore, simple randomization may lead to imbalances in the number of participants randomized for each group [3]. In a small samples trial, simple randomization is not a good option for the trial. Blocked randomization may be a better choice for a small sample trial, for example, this study.

On the other hand, authors should report the basis for the calculation of sample size according to the CONSORT statement [4]. The authors should consider the balance between medicine and statistics, which will be a bridge of scientific study and ethical requirements. The authors did not disclose how they determined the sample size, so we cannot evaluate whether the study reached a reasonable balance. 


\section{Acknowledgement}

We thanks Danghan Xu for his advice in this letter writing.

\section{Conflict of Interest Statement}

The authors have no conflicts of interest to declare.

Funding Sources

No funding

\section{Author Contributions}

Yunxuan Huang proposed the concept and reviewed the manuscript. Menghua Li wrote the first draft. Zhaoxi Liu revised the manuscript.

\section{References}

1 Hasanpour-Dehkordi A, Kabiri F, Dris F. Comparing the Effects of Massage Therapy and Aromatherapy on Knee Pain, Morning Stiffness, Daily Life Function, and Quality of Life in Patients with Knee Osteoarthritis. Vergleich der Wirkung von Massagetherapie und Aromatherapie im Hinblick auf Knieschmerzen, Morgensteifigkeit, Funktionsfähigkeit im Alltag und Lebensqualität bei Patienten mit Osteoarthritis des Kniegelenks. Complement Med Res. 2021;28(4):292-299.

2 Felipe F, Ben I. Critical Thinking in Clinical Research. 1st ed. New York: Oxford University Press; 2018.

3 Kang M, Ragan BG, Park JH. Issues in outcomes research: an overview of randomization techniques for clinical trials. J Athl Train. 2008;43(2):215-221.

4 Schulz KF, Altman DG, Moher D, for the CONSORT Group. CONSORT 2010 statement: updated guidelines for reporting parallel group randomized trials. Obstet Gynecol 2010;115(5):1063-70 